Dossiê

\title{
NORMA E DESVIO: CIÊNCIA E SOCIEDADE NA PRODUÇÃO DA ORDEM
}

\author{
Valesca Daiana Both Ames ${ }^{1}$ \\ Fabrício Monteiro Neves ${ }^{2}$
}

\begin{abstract}
RESUMO
O artigo pretende relacionar e comparar as teorias sociológicas de Émile Durkheim e David Bloor no que diz respeito às suas concepções sobre ordem e desvio, levando-se em conta que o primeiro argumenta em um nível social mais amplo e o outro busca compreender a dinâmica científica. Em um plano intermediário situamos Thomas Kuhn, visto que este busca transpor elementos verificados em um plano social para uma análise no âmbito da ciência. $\mathrm{O}$ foco do artigo constitui-se em ver como os autores elaboram uma teoria normativa onde os indivíduos seguem um determinado padrão de ações, definido através de regras e atitudes sancionadas. De acordo com os autores supracitados, as normas, ou regras de conduta, se instituem como algo coercitivo e interiorizado pelos agentes. O que aqui se pretende sustentar é que os autores se aproximam no que diz respeito ao elemento mantenedor da ordem social e quanto ao tratamento dos casos que fogem da regra. Ilustraremos este argumento com o caso do físico português João Magueijo, que buscou contestar um dos pilares da física contemporânea.
\end{abstract}

Palavras-chave: Norma - Desvio - Ciência - Sociedade.

\begin{abstract}
The paper intends to relate and compare the sociological theories of Emile Durkheim and David Bloor in respect to their conceptions of order and deviation, taking into account that the first argues in a broader social level and the other seeks to understand the scientific dynamics. In an intermediary plane we situate Thomas Kuhn, whereas he seeks to transpose elements checked in a social plan to a scientific scope analysis. The focus of the article is in seeing how the authors elaborate a normative theory where individuals follow a certain pattern of actions, defined by rules and sanctioned attitudes. According to the aforementioned authors, the norms or rules of conduct, establish themselves as something coercive and internalized by the agents. What is intended here to state is that the authors agree in what regards the element that maintains the social order and how to deal with cases that are beyond the norm. We illustrate this argument with the case of the portuguese physicist João Magueijo, who sought to challenge one of the pillars of contemporary physics.
\end{abstract}

Keywords: Norm- . Deviation - Science - Society.

\footnotetext{
${ }^{1}$ Mestre em Sociologia pela Universidade Federal do Rio Grande do Sul (UFRGS) e doutoranda em Sociologia na mesma instituição. Endereço eletrônico: valesca.ames@gmail.com

${ }^{2}$ Doutor em Sociologia pela Universidade Federal do Rio Grande do Sul (UFRGS). Professor da Universidade de Brasília. Endereço eletrônico: fabriciomneves@gmail.com
} 


\section{Norma e Desvio: ciência e sociedade na produção da ordem \\ INTRODUÇÃO}

"A necessidade lógica é uma espécie de obrigação moral"

David Bloor, em Conhecimento e imaginário social

O presente artigo insere-se na área de estudos denominada sociologia do conhecimento científico, desenvolvida a partir da década de 1970, que tem como trabalho pioneiro a obra de Thomas Kuhn intitulada A estrutura das revoluções científicas. Com o desenvolvimento da nova sociologia da ciência, esta amplia seu campo de pesquisa, analisando o conteúdo e a natureza das teorias científicas, elementos considerados anteriormente como passíveis apenas de uma explicação filosófica. Esta mudança com relação às possibilidades da sociologia na análise da ciência foi sistematizada através do chamado programa forte em sociologia do conhecimento científico, cunhado por David Bloor e que se constitui como um programa de pesquisa que tem como objetivo nortear o trabalho sociológico na explicação de formas verdadeiras e falsas de conhecimento.

O tratamento diferenciado entre a filosofia e a sociologia na análise da ciência expressa uma diferenciação entre verdade e erro, como resultado de dicotomias entre irracionalidade/racionalidade, ignorância/sabedoria, superstição/conhecimento, sociedade/natureza. Estas falsas polaridades entre sociedade e natureza expressam uma separação entre a racionalidade humana salvaguardada pela objetividade científica e analisável pela filosofia e a irracionalidade dos homens, influenciados por suas crenças e paixões, frutos da vida em sociedade ${ }^{3}$.

Esta diferenciação, além do mais, pode ser apresentada como a contradição entre os contextos da descoberta e da justificação. No contexto de justificação encontramos os enunciados e métodos de verificação e aceitação de uma teoria. No contexto de descoberta são abordados os aspectos factuais, a ação da imaginação e criatividade que constituem o processo de gênese destas. A análise sociológica da ciência ficaria restrita ao contexto da descoberta, onde "algo" (ligado a fatores sociais) teria desviado o caminho natural do cientista em busca da "verdade". A divisão entre análises sociológicas e filosóficas da ciência expressa um tratamento assimétrico desta, pois julga-se que somente necessita de explicação aquele

\footnotetext{
${ }^{3}$ Sublinhamos aqui que essa assimetria na análise científica era sustentada pelos filósofos que faziam parte do chamado Círculo de Viena, como Moritz Schlick, Rudolf Carnap, por exemplo, e ainda por filósofos como Karl Popper, não sendo generalizável a todas as correntes de pensamento filosófico. No que diz respeito à sociologia, a assimetria somente foi criticada de forma radical com a emergência do que se denomina nova sociologia do conhecimento científico, que se desenvolveu a partir da década de 1970.
} 


\section{NORUS v1, n.2, jan-jun 2014.}

algo que causou o desvio da linha reta, uma vez que a racionalidade não precisava de explicação alguma (LATOUR, 2000).

A assimetria na análise do conhecimento apenas foi superada com o desenvolvimento da teoria kuhniana a respeito da ciência, e que posteriormente influenciou o programa forte. A partir de então a sociologia não se vê mais restrita à análise dos fatores externos que influenciam a produção do conhecimento, mas torna-se capaz de analisar o conteúdo deste. Assim, “os chamados aspectos 'internos' do desenvolvimento científico, isto é, os pertencentes classicamente ao contexto da justificação, passaram a também caber no escopo de questões tratadas por meio de critérios sociológicos” (DUARTE, 2007, p. 32).

Portanto, não temos mais uma divisão entre sociedade e natureza, mas sim uma mistura entre homens e coisas, entre conteúdo e contexto. Desta maneira, podemos afirmar que aspectos relacionados ao contexto social, como interesses econômicos, interesses políticos, controvérsias, negociações, fazem parte da estruturação do conhecimento. Esta afirmação, entretanto, ao contrário do que se considerava anteriormente, não deturpa a "verdade" do conhecimento, mas apresenta-se como algo intrínseco a ele.

Tomando como referência esta abordagem do conhecimento e desta forma, a indiferenciação entre os contextos, buscamos compreender a forma pela qual o conhecimento é mantido dentro de um determinado contexto social, e a maneira com que o indivíduo se liga a estas coletividades. O fio condutor da análise a ser aqui desenvolvida refere-se ao argumento de que os autores Emile Durkheim, Thomas Kuhn, Harry Collins e David Bloor aproximam-se quando teorizam sobre as formas de manutenção da ordem social e científica, visto que elaboram uma teoria normativa do fazer social e científico, procurando demonstrar que as formas de entendimento do mundo possuem uma base social.

A ciência, assim como a sociedade, desenvolveria um conjunto de regras para controlar a crença dos indivíduos, o que incide no conteúdo do conhecimento. Como as pessoas infringem questões de dever e legalidade, também o fazem em questões de compulsão lógica, desta forma, o conhecimento considerado verdadeiro também pode ser questionado, suscitando controvérsias entre cientistas. Em ambas as situações, os comportamentos que não se conformam ao estabelecido socialmente acabam segregados, excluídos, rotulados. Porém, tanto as infrações quanto as anomalias, que suscitam as controvérsias, constituem-se como elementos importantes relacionados a ambas as lógicas, pois as tornam dinâmicas, passíveis de mudança.

Este trabalho está dividido em quatro partes. Na primeira tomamos como referência a obra de Emile Durkheim, intitulada As formas elementares da vida religiosa, na qual o autor 


\section{Norma e Desvio: ciência e sociedade na produção da ordem}

realiza uma análise do papel da religião como fonte mantenedora da integração social. Seguindo na mesma direção, Harry Collins procura compreender a maneira pela qual o conhecimento constitui-se de maneira estável na sociedade e depois transpõe isto para a análise da ciência, formulando a hipótese segundo a qual a sanção dos experimentos como critério de demarcação entre o que é e o que não é científico faz com que a ciência se desenvolva de maneira estável.

David Bloor, no mesmo sentido de Durkheim, mostra de que maneira o conhecimento matemático constitui-se convencionalmente, tornando-se um modo institucionalizado de pensar, onde uma matemática alternativa apresenta-se como um erro ou inadequação à norma. Dessa maneira, Bloor, e podemos dizer também Thomas Kuhn, ressalta a importância do consenso para o desenvolvimento científico e aponta a existência de fatores tipicamente sociais como a argumentação e a persuasão na aceitação ou rechaço de uma teoria, mostrando que a atividade científica não é diferenciada de outras atividades sociais.

Por fim, o trabalho de João Magueijo servirá como um estudo de caso, no qual apresentamos uma teoria desconsiderada no âmbito científico, mais especificamente, na área da ciência física, e que, recentemente, deu provas de que não é totalmente "incorreta". Esta exposição poderá contribuir na elucidação dos mecanismos sociais que entram em jogo quando uma nova teoria, diferentemente daquela que então serve como paradigma, é defendida por um membro da comunidade científica.

\section{UMA ANÁLISE DA RELIGIÃO COMO FATO SOCIAL}

$\mathrm{O}$ artigo procura sustentar o argumento de que, de acordo com uma determinada perspectiva, podemos afirmar que tanto a ciência quanto a sociedade constituem-se por uma uniformidade de pensamento e ação. Esta afirmação nos leva às seguintes indagações: como se produzem estas uniformidades? Que tipo de analogia se pode buscar entre os processos de permanência e mudança típicos da ciência, e os que se desenrolam na vida social? Revela-se importante comparar os mecanismos que levam à criação de consenso no interior da ciência com os fatores responsáveis pela integração social.

Com a finalidade de responder essas questões, iremos, em um primeiro momento, analisar a forma como se produzem os modos de pensamento e ação sancionados socialmente. Para tanto, partimos da análise da obra do sociólogo Emile Durkheim, considerado um dos fundadores da sociologia do conhecimento, visto que afirma a possibilidade de uma 


\section{NORUS v1, n.2, jan-jun 2014.}

explicação sociológica do saber a partir de sua base social, mostrando "como um sociólogo é capaz de adentrar as profundezas de uma forma de conhecimento" (BLOOR, 2008, p. 160).

Dentre suas idéias uma foi de enorme importância para o desenvolvimento posterior desta área de estudos. Esta diz respeito à consideração de que determinados conceitos e categorias, usados para entender o mundo, possuem uma origem social, ou seja, dependem dos estados da coletividade e da organização social em que são formulados, sendo representações que as sociedades fazem de si mesmas. Assim, classificamos o mundo nos chamados gêneros porque temos o exemplo das sociedades humanas. Esta hipótese mostra a importância da dimensão social na estruturação e estabilidade do conhecimento, sendo este considerado como a maneira coletiva e institucionalizada de pensar, e que impõe regras e condutas aceitas socialmente e que definem a maneira com que o indivíduo deve comportarse, sendo desta forma normativas (DURKHEIM, 1996).

Este conjunto de crenças e sentimentos comuns à media dos membros de uma coletividade, que constituem hábitos coletivos, exprimidos por um "conjunto de regras definidas que determinam o comportamento de forma imperativa" (LALLEMENT, 2003, p. 202), é o que define a consciência coletiva em Durkheim, e que se constitui como uma forma de moralidade. A consciência coletiva condena alguns modos de comportamento, pois esses ferem sentimentos fundamentais para a existência e a estabilidade da vida social.

Assim, o indivíduo considerará boa uma prática que é aceita pela coletividade. $\mathrm{O}$ ator social crê, diz-nos Durkheim, naquilo em que crêem as pessoas que o rodeiam, porque se identifica com o grupo e incorpora os valores deste. Assim, "os conceitos são representações que se impõem aos indivíduos porque são representações coletivas" (ARON, 2008, p. 517). A coletividade impõe ao indivíduo normas que este interioriza no curso da sua socialização, que se dá através da educação que é, em essência, um fenômeno social, pois depende da estrutura da própria sociedade. Desta forma, educar um indivíduo é prepará-lo para participar de uma ou de várias comunidades, tornando-os conscientes das normas que devem orientar a conduta de cada um. Esta disciplina deve ter um caráter autoritário, ao mesmo tempo em que é desejada, visto que provém do próprio grupo social.

Dado que é o pensamento coletivo que torna possível a vida social, e que se diferencia das consciências individuais, Durkheim afirma a importância deste ser estudado em si mesmo, para isto, define aquilo que caracteriza os fatos sociais a partir do exterior, a saber: a possibilidade de exercer uma coerção sobre os comportamentos individuais que a ele não se conformam. A fim de ilustrarmos a maneira pela qual os fatos sociais coagem e estruturam a vida social, tomaremos como base a obra durkheimiana intitulada As formas elementares da 


\section{Norma e Desvio: ciência e sociedade na produção da ordem}

vida religiosa (1996), onde o autor busca entender a natureza religiosa do homem. Para tanto, Durkheim analisa a religião considerada mais primitiva, sendo esta caracterizada por dois aspectos: de não ser ultrapassada por nenhuma outra em sua forma de organização e de ser explicável sem se fazer intervir nenhum elemento tomado de uma religião anterior. $\mathrm{O}$ totemismo é a religião elementar na qual o autor empreende sua análise.

Para Durkheim a religião é concebida como um fato social, ou seja, possui um caráter coercitivo, externo e geral, impondo-se às individualidades. Este caráter imputado ao pensamento religioso vai ao encontro da análise de Bloor a respeito da ciência, sendo esta um produto coletivo, dotado de um poder de coerção sobre os indivíduos e geral em sua extensão. Cada um destes elementos característicos do fato social será explicado através da exposição da análise de Durkheim a respeito da religião enquanto instituição social.

O caráter geral característico das crenças religiosas se deve ao fato de que elas são comuns a uma coletividade, traduzindo-se por uma uniformidade intelectual e moral. $\mathrm{O}$ caráter externo pode ser observado no fato de que as categorias utilizadas para compreender o mundo não são produtos individuais, mas sim representações coletivas, obra da comunidade e que dependem da maneira como está organizada a sociedade. Por outro lado, a própria sociedade depende, para manter-se, desta uniformidade de pensamento. Collins, da mesma forma, afirma que

\footnotetext{
A sociedade, para poder manter-se, requer com freqüência que vejamos as coisas sob um certo ângulo, que as sintamos de um certo modo; conseqüentemente, modifica as idéias que seríamos levados a ter dessas coisas, os sentimentos a que estaríamos inclinados se obedecêssemos apenas à nossa natureza animal (COLLINS, 2009, p.55).
}

Estas categorias utilizadas para compreender o mundo são estáveis e gerais porque despertam no indivíduo um sentimento de necessidade e de respeito. A ideia de necessidade pode ser expressa pelo fato de que uma categoria impõe-se ao pensamento sem nem ao menos ser acompanhada por alguma prova objetiva de seu funcionamento ou de sua correspondência com o mundo empírico. O respeito pode ser observado pelo fato de que estas crenças, quando não seguidas, tornam-se motivo de repulsa por parte de outros membros que constituem o grupo social.

Outra característica das representações coletivas aponta para seu caráter estável, pois apenas acontecimentos de suficiente gravidade poderiam afetar a base mental da sociedade. As categorias podem resistir às mudanças até mesmo se estas se contrapõem à experiência. 
Seria uma forma de pensar que está fixa e cristalizada, visto que se encontra no plano da coletividade. De acordo com Durkheim, no âmbito do conhecimento científico:

O cientista se encontra na mesma situação em face da terminologia especial empregada pela ciência a que se dedica e, consequentemente, em face do sistema especial de conceitos ao qual essa terminologia corresponde.[...] Claro que ele pode inovar, mas suas inovações são sempre uma espécie de violência praticada contra maneiras de pensar instituídas (DURKHEIM, 1996, p. 481).

O indivíduo não poderia libertar-se destas noções sem que algo resistisse a ele, não pode, portanto, formular representações sobre o mundo independentemente das outras crenças que se encontram no conjunto da sociedade. Em outras palavras: se o nativo se comporta desta ou daquela maneira com os seres totêmicos, não é somente porque as forças que neles residem são em princípio fisicamente temíveis, é porque ele "se sente moralmente obrigado a comportar-se assim, tem o sentimento de que obedece a uma espécie de imperativo, de que cumpre um dever" (DURKHEIM, 1996, p. 192). Esta característica do fato social constitui o que Durkheim aponta como seu caráter coercitivo.

Torna-se importante lembrarmos aqui que a maneira com que a sociedade reage "por meio da censura ou da repressão material, contra as tentativas de dissidência, manifestando com intrépido o ardor da convicção comum, contribui para reforçar seu domínio" (DURKHEIM, 1996, p. 213), reforçam, desta maneira, a própria coesão e integração social. As crenças compartilhadas possuem um caráter sagrado, pois traduzem o modo como as forças coletivas agem sobre as consciências individuais, não sendo permitido contestá-las ou negá-las sem sofrer uma espécie de censura ou repressão social.

Se as violamos [as regras morais], corremos o risco de sermos postos à margem, de quarentena, isolados. Já não falarão conosco da mesma maneira, não nos tratarão do mesmo modo, demonstrar-nos-ão uma estima menor e nos manifestarão até mesmo desprezo. (DURKHEIM, 2007, p. 64)

A religião, então, além de uma forma de concepção do mundo, também compreende "regras de conduta que prescrevem como o homem deve comportar-se com as coisas sagradas" (DURKHEIM, 1996, p. 24). Devemos ter em conta que o âmbito do sagrado é definido como o próprio âmbito da sociedade, sendo que o totem, que representa a sociedade, define o que é considerado sagrado e profano para uma dada coletividade e torna possível a vida social.

Procuramos entender a dimensão normativa do pensamento do autor visto que a religião funciona como uma espécie de moralidade, sendo definida por um conjunto de regras, 


\section{Norma e Desvio: ciência e sociedade na produção da ordem}

que prescrevem como o indivíduo deve agir no mundo. Quando ele não age respeitando as regras, sente dentro dele um sentimento de protesto. Porém a moral não é apenas um sistema de regras que devemos seguir por medo de alguma coação exterior, mas sim porque sentimolas como boas, corretas, desejadas pelos indivíduos (DURKHEIM, 2007). Este compartilhamento de crenças e sentimentos tem como função integrar o corpo social, garantir sua unidade, através da conformação de todas as consciências particulares a uma consciência comum que é a consciência coletiva.

\section{CRIME E ANOMALIA NA PRODUÇÃO DA MUDANÇA}

A existência de uniformidades no interior dos grupos sociais é uma condição de existência destes, porém isso não significa que formas de vida e de fazer ciência não possam ser modificadas. A maneira pela qual ambas se modificam pode ser ilustrada através da análise do papel que possui na sociedade e na ciência os comportamentos e problemas considerados desviantes, como o crime e a anomalia, por exemplo.

Com a finalidade de basearmos a afirmação anterior na qual se argumenta que o consenso é uma condição para a existência da sociedade, partimos da obra de Harry Collins intitulada Changing Order. Collins afirma, logo no primeiro capítulo: "sem ordem não pode haver sociedade" (COLLINS, 2009, p. 19, tradução nossa). A partir disto, tenta compreender a maneira como a ordem se forma no interior dos grupos sociais, onde podemos englobar também o grupo de cientistas, ou ainda comunidade científica, como nomeia Thomas Kuhn.

De acordo com Collins a habilidade dos seres humanos para ver as mesmas coisas e para responder a elas de uma mesma maneira formam a base da cultura e da ordem social. "A existência de grupos depende da existência de uniformidades dentro deles. Ou seja, para haver sociedade deve haver ordem e uniformidades de percepção e significação do mundo.” (COLLINS, 2009, p. 19). Como Collins, Durkheim afirma que a religião serve como fonte de integração social, visto que ela produz e reforça os laços sociais de um dado grupo. As representações coletivas derivam da vida social e ao mesmo tempo são o fundamento desta, na medida em que emanam da sociedade e são instrumento de comunicação entre os indivíduos, fazendo-os compartilharem uma vida com valores e sentimentos comuns.

Collins afirma que vemos as coisas de uma maneira uniforme porque as noções ligadas às coisas, ou seja, as palavras que usamos para nomeá-las, adquirem um caráter estável, pois estão arraigadas às nossas práticas linguísticas, não podendo desta maneira, serem mudadas facilmente. "Nossa linguagem e nossa vida social estão tão entrelaçadas que 
nossos hábitos de linguagem ajudam a determinar o modo com que vemos o mundo e deste modo formam a base da interação social" (COLLINS, 2009, p. 29). Esta ideia de Collins vai ao encontro da análise de Wittgenstein a respeito do que ele chama "formas de vida", no interior das quais cada grupo estabelece um sentido diferente às mesmas palavras, e onde estas só podem ser entendidas em um contexto de uso específico, que diz respeito àquele grupo. Desta maneira,

para compreender o significado das palavras e das proposições, é preciso conhecer as regras do jogo dentro do qual tais palavras e proposições são usadas e, por sua vez, tais regras, que são o produto convencional do encontro intersubjetivo, não são independentes das formas concretas da vida e dos contextos sócio-culturais particulares (CRESPI; FORNARI, 2000, p. 185).

Portanto, os indivíduos interiorizam as regras através do processo social de aprendizagem a que são expostos e que os incorpora às formas de significação estabelecidas socialmente, integrando-os a um determinado grupo social. Assim, os hábitos podem ser expressos a partir de regras que são formuladas pelo grupo social, que podem não ser explícitas, pois já estão incorporadas ao modo de agir e fazer, ou seja, elas constituem-se como uma convenção social, e são seguidas porque adquirem este caráter.

Qualquer intenção de ocasionar uma mudança no uso ou na percepção requereria mudar toda uma rede de usos interrelacionados, percepções e relações sociais, por isso a dificuldade já mencionada de mudarmos uma determinada "forma de vida". Esta dificuldade pode ser transposta para a ciência, pois nesta a novidade emerge com dificuldade contra um pano de fundo fornecido pelas expectativas, neste sentido, Collins afirma que

A ciência, como qualquer outra atividade social, se baseia em um fundamento de realidade tida como certa, normal. Usualmente os cientistas vêem as coisas através do marco de referência que lhes foi dado quando foram formados, ou seja, os cientistas praticam a ciência tal como lhes foi mostrado na academia (COLLINS, 2009, p. 40)

Collins afirma esta uniformidade de pensamento e ação como pré-requisito para a existência dos grupos sociais e em um segundo momento transpõe isto para a análise da ciência. Pergunta-se como estas uniformidades se produzem dentro da lógica científica, chegando a conclusão de que isto se deve à legitimação dos experimentos como critério de demarcação entre o que é e o que não é verdadeiro.

Os experimentos servem para que o cientista se certifique da validade de suas teorias, onde pressupõem-se que determinados eventos seguem uma ordem, uma lógica, inerente ao 


\section{Norma e Desvio: ciência e sociedade na produção da ordem}

próprio fenômeno estudado. Porém, de acordo com Collins, os eventos não se repetem da mesma forma, a replicabilidade observada pelos cientistas deve-se a uma propensão a imputar causalidade entre os fenômenos, percebendo-os como regulares. A regularidade característica dos fenômenos científicos advêm da propensão a enxergar as coisas como estáveis, dada pela estabilidade das próprias formas de vida (nas quais são incluídas teorias, métodos, treinamento e linguagem) compartilhadas pelos cientistas. Os fenômenos repetem-se porque o vemos como passível de repetição. Esta característica proporciona o desenvolvimento e a estabilidade dos grupos que compõem as comunidades científicas, dado que fornece uma espécie de consenso entre seus membros a respeito do que é ou não científico.

Outros autores também apontam a importância do consenso para o desenvolvimento de práticas sociais e científicas, Thomas Kuhn, por exemplo, entende processos de treinamento e socialização como fundamentais para o desenvolvimento científico. Esta ideia é desenvolvida em seu livro intitulado A estrutura das revoluções científicas, que marcou o desenvolvimento das análises sociológicas da ciência.

Kuhn, ao tentar descobrir a fonte dos desacordos existentes entre os cientistas sociais quanto aos métodos e problemas científicos legítimos, reconhece a importância, na ciência, do que ele chama "paradigma". Assim, em Kuhn:

O consenso [de uma comunidade científica] se expressa por intermédio de crenças mais ou menos compartilhadas pelos membros de uma sociedade. Varia em função da diferente intensidade de adesão que cada tipo de crença se mostra capaz de suscitar. (OLIVA, 1999, p. 213).

De acordo com Kuhn, em toda organização dedicada à produção de conhecimento existiria um sistema complexo de normas sociais que regulariam a produção deste. Os cientistas trabalhariam a partir de modelos adquiridos através da educação ou da literatura a que são expostos, o que lhes permitiria a adesão a um determinado paradigma e a resolução de problemas propostos por este. Isto caracterizaria a chamada ciência normal, onde encontramos "uma sólida rede de compromissos e adesões - conceituais, teóricas, metodológicas e instrumentais" (KUHN, 1998, p. 65). A ciência normal, portanto, diz respeito à tradição de pesquisa que se desenvolve em torno de um paradigma e que define os problemas e as soluções destes para uma determinada comunidade de cientistas.

Os cientistas, muitas vezes, não conhecem as características que proporcionam o status de paradigma comunitário aos modelos da ciência normal, por atuarem assim, eles não precisam de regras explícitas. Enquanto os paradigmas são seguros, eles podem funcionar sem que haja necessidade de um acordo sobre as razões de seu emprego ou mesmo sem qualquer 


\section{NORUS v1, n.2, jan-jun 2014.}

tentativa de racionalização. Porém, a ciência normal pode avançar sem regras somente enquanto a comunidade científica relevante aceitar sem questões as soluções de problemas específicos já obtidos. As regras assumem importância sempre que os paradigmas forem contestados ou pareçam inseguros.

Desta forma, sempre que há uma contestação do modelo de ciência normal seguido por uma comunidade científica, torna-se proeminente a emergência das regras que sustentam as pesquisas desenvolvidas. Com a consolidação de um paradigma, há um conjunto-padrão de métodos ou de fenômenos que todos os estudiosos da área se sentem forçados a empregar e a explicar ${ }^{4}$. Para ser expulso de uma comunidade científica, há poucas formas mais seguras que pôr em questão os esquemas de trabalho intelectual sedimentado. Os que se recusam a proceder conforme os procedimentos prescritos pelo paradigma, acabam excluídos dos grupos da comunidade científica.

Portanto, a existência da comunidade científica sugere uma forma de solidariedade social e um modo de vida específico, com seus próprios estilos, hábitos e rotinas, que constituem um conjunto de práticas concretas, a serem seguidas pelos membros do grupo. As ideias científicas individuais são sempre parte do "todo" abrangente de uma tradição de pesquisa.

A noção de ciência normal pode, em parte, ser aprofundada aproximando-a de algumas formas de normalidades detectáveis em planos da vida social. Para sustentarmos esta relação, tomamos o conceito de Durkheim a respeito do que constitui-se como fenômeno normal e patológico dentro da lógica social.

Durkheim, procurando estabelecer um objeto específico para a sociologia, que se diferenciasse dos objetos estudados pelas outras ciências, define os chamados fatos sociais. Os fatos sociais podem ser visualizados pelos cientistas devido a sua generalidade, são os chamados fenômenos normais. Quando encontrados em uma minoria de vezes, são denominados fenômenos patológicos, estes últimos perturbam o desenrolar normal das funções do organismo social, fazendo surgir um resultado que é nocivo para a sociedade (DURKHEIM, 2002).

Um fenômeno determinado caracteriza-se como normal não porque seja útil ao organismo, mas porque está ligado às condições de existência da sociedade, implicando uma

\footnotetext{
${ }^{4}$ Merton também enfatiza o papel das normas como determinantes nos processos de integração dos grupos de cientistas. Para o autor, "as regras metodológicas que obrigam o cientista a fornecer evidências empíricas e consistência lógica nos resultados estão revestidas por normas morais apoiadas socialmente e possibilitam à ciência cumprir sua meta institucional de ampliação do conhecimento certificado" (MATTEDI; SPIESS, 2010, p. 75). Estas normas e valores, que orientam a prática científica, formam aquilo que o autor denomina ethos científico.
} 


\section{Norma e Desvio: ciência e sociedade na produção da ordem}

determinada forma de ordem e de organização social. Esta consideração aproxima-se da concepção kuhniana de ciência normal, pois esta não se institui por ser uma forma mais útil de compreensão do mundo, mas por resolver os problemas considerados mais importantes em um determinado momento do desenvolvimento científico.

De acordo com a concepção de Durkheim, o crime deve ser considerado como um fenômeno normal, visto que é encontrado em todas as sociedades, apresentando formas anormais apenas quando atinge taxas elevadas. A existência da criminalidade é parte integrante de toda a sociedade sã, sendo totalmente impossível uma sociedade que se mostre isenta do crime (DURKHEIM, 2002). Da mesma forma, de acordo com Kuhn, a anomalia também pode ser considerada como um fenômeno normal, visto que acompanha sempre o desenvolvimento de um paradigma, e só adquire a capacidade para gerar crise sob condições especiais, quando gera controvérsias entre cientistas a respeito de sua adequação com relação às explicações dos fenômenos a que se propõem analisar. As anomalias, segundo Kuhn, somente são superadas com o desenvolvimento de uma outra forma de prática científica, que emerge através de negociações intergrupais, treinamento e desnível de poder entre as comunidades científicas.

De acordo com Durkheim, quanto mais homogênea for uma estrutura, ou seja, quanto mais uma determinada prática ou crença seja uniforme, mais oporá resistência a qualquer modificação. A uniformidade de crenças e sentimentos coletivos comuns a média dos membros de uma sociedade constitui o que Durkheim denomina consciência coletiva, e é esta que o crime fere, quando praticado. Ele é visto, nestas condições, como imoral e levará a uma repreensão sobre aquele que o cometeu. Da mesma forma, a ciência, de acordo com a perspectiva aqui explorada, repreende teorias inovadoras que se contrapõem àquela que serve como paradigma para uma dada comunidade de cientistas, o que será demonstrado através da análise do caso do físico Magueijo, quando este elabora uma teoria que se contrapõe ao paradigma físico moderno.

Para que os crimes deixassem de ser cometidos, seria necessário uma uniformidade universal e absoluta das crenças, o que se mostra impossível, pois as influências sociais de que dependemos variam de um indivíduo para outro e, por conseguinte, diversificam as consciências (DURKHEIM, 2002). Para Durkheim, a possibilidade de consenso total é remota mesmo em pequenas unidades sociais, e se torna ainda mais improvável em sociedades complexas. Por isso, teríamos sempre os comportamentos caracterizados como desviantes para uma dada sociedade. 


\section{NORUS v1, n.2, jan-jun 2014.}

De acordo com Durkheim, fenômenos sociais como o direito e a moral, por exemplo, variam de um tipo social para outro, e se modificam se as condições de existência coletiva, como a organização social, se modificarem, pois estes fenômenos são derivados da associação dos homens. No mesmo sentido, porém no plano científico, Kuhn observa que a ciência considerada legítima também pode apresentar variações entre as comunidades científicas que não compartilham do mesmo paradigma. Assim, as formas de vida variam de acordo com as regras que são compartilhadas, com a emergência de um novo paradigma, estas também sofrem modificação. Porém, tanto no âmbito da lógica social quanto no âmbito da lógica científica, para que as transformações sejam possíveis, é preciso que os sentimentos coletivos que estão na base da moral (ou do paradigma na análise de Kuhn), não sejam refratários à mudança e não apresentem, por conseguinte, senão uma energia moderada.

O crime, por exemplo, "mostra que o caminho está aberto para mudanças necessárias, como também prepara diretamente estas mudanças" (DURKHEIM, 2002, p. 61). Pode ser uma antecipação da moral que está por vir. Da mesma forma, uma anomalia pode abrir espaço para a emergência de um novo paradigma. Sua resolução pode levar à emergência de novas regras que orientarão a ciência normal, que se constitui como uma nova forma de normalidade, e uma nova forma de vida coletiva.

Portanto, as mudanças que ocorrem tanto na ciência quanto na sociedade, sob a vigência de uma norma, só são possíveis porque ambas não se constituem por uma homogeneidade total de crenças. Os indivíduos violam as regras antes destas serem solenemente repudiadas. Para a mudança social, assim como para a mudança científica, acaba tornando-se importante a existência dos comportamentos desviantes, pois eles fazem com que ambas tornem-se dinâmicas. A ciência normal, por exemplo, incorpora o elemento que gerará a sua própria mudança (anomalias).

\section{AUTORIDADE MORAL E AUTORIDADE LÓGICA}

O sociólogo da ciência David Bloor afirma que o conteúdo do conhecimento científico pode ser alvo de explicação sociológica, assumindo uma posição reflexiva quanto à maneira com que o conhecimento se mantém e adquire um status privilegiado em um determinado contexto social. De acordo com Bloor, a ciência, assim como a sociedade, aparece, à primeira vista, como a forma mais estável e intocável de conhecimento, visto que se encontra no plano da coletividade. Porém, a ciência também comporta elementos que propiciam a sua modificação, como salientado anteriormente. Com a finalidade de esclarecer 


\section{Norma e Desvio: ciência e sociedade na produção da ordem}

estas duas questões, Bloor parte para a análise do conhecimento matemático. Pergunta-se então o sociólogo: como pode tal conhecimento adquirir uma forma tão estável? Seria possível a idéia de uma matemática alternativa?

Bloor, tendo elaborado uma abordagem simétrica do conhecimento científico, através da consideração de elementos sociais e empíricos na análise da ciência, afirma que o conhecimento é uma forma de entender o mundo, tendo este mesmo mundo como base de suas formulações. Desta maneira, uma determinada forma de compreensão do mundo adquire o status de conhecimento não apenas por apresentar uma melhor adequação entre a teoria e o mundo, mas também por sua capacidade de produzir um consenso entre os membros de uma comunidade científica.

Deste modo, a forma com que o consenso se produz pode ser explorada através do entendimento da maneira pela qual o conhecimento adquire o status de instituição social. A concepção sociológica da ciência elaborada por Bloor servirá como referência a fim de constituirmos um paralelo entre as regras científicas e sociais. No que se refere à dimensão social, tomamos como categoria de análise o conceito de fato social, elaborado pelo sociólogo Émile Durkheim, e já apresentada em sua interpretação a respeito da origem e da natureza da experiência religiosa, que influenciou a abordagem desenvolvida por Bloor.

Como afirmado anteriormente, o poder de coerção característico dos fatos sociais, na análise de Durkheim, não se faz sentir quando o indivíduo procede conforme as regras, pois neste caso, torna-se inútil. Porém, quando um indivíduo tenta resistir ao que está socialmente sancionado, logo é repreendido. As regras, portanto, constituem-se como caráter intrínseco de tais fatos, visto que "se este poder de coerção externa se afirma com tal nitidez nos casos de resistência, é porque, mesmo inconsciente, existe também nos casos contrários" (DURKHEIM, 2002, p. 04). Esta característica aproxima os fatos sociais ao paradigma kuhniano, visto que as regras sempre acompanham o desenvolvimento científico, constituindo-se como uma característica implícita da ciência normal, pois somente são racionalizadas quando contestadas.

Bloor baseia-se na noção de fato social para construir sua ideia de conhecimento, contrapondo-se a análise filosófica tradicional que o define como uma crença verdadeira e justificada, pois "segundo esta concepção, a verdade não é verdade em relação com esta ou aquela pessoa. Antes, provém de como as coisas são realmente no mundo, independentemente, talvez, das crenças dos seres humanos" (MOSER; MULDER; TROUT, 2004, p. 73).

Desta forma para Bloor, 
Conhecimento é aquilo que está no plano do coletivo, da sociedade, enquanto que as crenças são individuais, idiossincráticas [...]. Não deve ser pensado como o produto de mentes individuais, mas como um fenômeno coletivo. Além disso, é capaz de se impor às individualidades, assim como as regras morais. Assim, Bloor entende que o conhecimento não é crença justificada, mas qualquer conjunto de crenças que exista no plano da coletividade (DUARTE, 2007, p.42-43).

Porém, temos que lembrar que de acordo com o autor não é somente a sociedade que fornece a base de nossas teorizações sobre o mundo, a experiência também cumpre um papel muito importante em sua compreensão. Bloor não privilegia nem a esfera social nem a esfera natural na explicação do conhecimento, elaborando uma sociologia simétrica em relação a estas duas dimensões. Para o autor a verdade também se refere a alguma crença que corresponde à realidade, pois "uma sociologia consistente não poderia jamais apresentar o conhecimento como uma fantasia sem relação com nossas experiências do mundo material que nos cerca" (BLOOR, 2008, p. 59). Neste sentido, Bloor aproxima-se de Durkheim quando este último afirma que

Não basta que [os conceitos] sejam verdadeiros para que sejam aceitos. Se não se harmonizarem com as outras crenças, as outras opiniões, em uma palavra, com o conjunto das representações coletivas, serão negados, é como se não existissem (ARON, 2008, p. 518).

A experiência atua sobre o estado de crença, podendo levar a sua modificação, mas não exclusivamente, pois é a vida coletiva que permite justificar a existência dos conceitos e das categorias. O conhecimento é tomado como uma forma social de pensar, visto que é compartilhado entre os membros da sociedade. "Isso implica que uma determinada pessoa de uma dada sociedade não pode, simplesmente, mudar as formas cognitivas socialmente sancionadas a seu bel-prazer" (DUARTE, p. 42, 2007). Nas palavras de Bloor:

\begin{abstract}
A experiência individual ocorre dentro de um quadro de pressupostos, critérios, propósitos e significados que são compartilhados. A sociedade fornece essas coisas à mente individual e proporciona, ainda, as condições segundo as quais elas podem ser sustentadas e fortalecidas. Se o domínio de um indivíduo sobre elas fraquejar, há instituições prontas a lembrá-lo. Se sua visão de mundo começar a divergir, há mecanismos que encorajam o realinhamento. As necessidades de comunicação ajudam a manter padrões coletivos de pensamento na psique individual. Do mesmo modo, na experiência sensorial do mundo natural, constata-se algo que aponta para além dessa experiência, que lhe proporciona um quadro geral e lhe confere um significado maior (BLOOR, 2008, p. 32-33).
\end{abstract}

A estabilidade de qualquer concepção teórica sobre o mundo deve-se à sua dimensão social, pois os cientistas são treinados de determinada maneira e seus interesses e expectativas 


\section{Norma e Desvio: ciência e sociedade na produção da ordem}

são dotados de certa estrutura, que condiciona futuras observações, assim, "eventos não esperados ocorrem abaixo de seus olhos e não são vistos, ou são vistos, mas não suscitam respostas" (BLOOR, 2008, p. 46). A mesma afirmação pode ser encontrada na teoria kuhniana, visto que o autor argumenta que muitas vezes as anomalias não são vistas pelos cientistas, pois a emergência destas depende também de outros fatores, que não dizem respeito somente a uma não correspondência da teoria com a realidade.

Porém, o fato de uma concepção adquirir o status de instituição social não impede que se desenvolvam visões que contrariam a socialmente sancionada, aliás, para Bloor, a dinâmica científica é um dos elementos indispensáveis para o conhecimento. Uma forma lógica diferente da nossa é possível, desde que esta seja igualmente fundamentada, ou seja, desde que tal abordagem se fundamente em um componente social.

Em sua exposição a respeito da possibilidade de formulação de uma matemática alternativa, Bloor expõe o modo com que o conhecimento matemático foi considerado ao longo do tempo. Neste sentido, demonstra como controvérsias marcaram, em certa fase de seu desenvolvimento, esta área de estudos, em especial, analisa as concepções de John Stuart Mill e Johann Gottlob Frege, visto que ambos possuíam uma visão divergente da matemática.

Se de um lado temos a concepção indutivista e empirista que marca o pensamento de Mill, de outro Frege defende uma abordagem dedutivista e demonstra a maneira com que o conhecimento matemático assume seu caráter estável. Se para Mill a matemática é passível de interpretações divergentes de acordo com cada indivíduo, para Frege ela adquire o status de instituição social e, portanto, deve ser encarada de uma maneira uniforme. A crença institucionalizada satisfaz a definição de Frege do que considera objetivo.

A crítica que Frege dirige à Mill refere-se ao fato de que este último não faz jus à objetividade do conhecimento matemático, não tornando compreensível a natureza obrigatória de suas passagens, "não explica o porquê de as conclusões matemáticas parecerem como se não houvesse a possibilidade de serem outras em vez delas" (BLOOR, 2008, p. 160). A obrigatoriedade das passagens matemáticas deve-se justamente à sua dimensão social, visto que os hábitos cognitivos impõem a aparência de veracidade às proposições matemáticas.

Bloor, portanto, parte do mesmo pressuposto teórico sustentado por Frege, qual seja: o de que o caráter estável do conhecimento deve-se a sua base social. A objetividade do conhecimento é resultado da forma com que este é visto socialmente e não de algum suposto significado real dos conceitos. Coisas que adquirem o caráter de instituição social apresentam-se como objetivas. 


\title{
NORUS v1, n.2, jan-jun 2014.
}

Se o aspecto matemático de uma situação é justamente o aspecto convencional, social, podemos imaginar a existência de uma forma cognoscitiva divergente da nossa, vejamos então como isto se expressa através da análise de Bloor a respeito da noção de uma matemática alternativa.

Pode-se analisar a hipótese de existência de uma matemática alternativa, em comparação com um comportamento social desviante. Estas duas formas de desvio nos levam por caminhos não habituais, e são vistos como moralmente negativos. O conhecimento matemático expressaria de uma maneira bem definida a distinção entre o erro e a verdade, o indivíduo deve aprender a maneira institucionalizada, e por isso, correta, de agir no âmbito desta disciplina. O conhecimento adquire, desta maneira, uma forma estável.

A matemática se constituiria em um poder de coerção externa sobre aqueles que não seguem suas regras lógicas ${ }^{5}$. A presença deste poder é reconhecível, seja pela existência de alguma sanção determinada, seja pela resistência que o fato opõe a qualquer empreendimento individual que tenda a violentá-lo. Este "caráter persuasivo de uma regra reside apenas no hábito ou na tradição de que alguns modelos são usados em vez de outros." (BLOOR, 2008, p. 206). Desta forma,

\begin{abstract}
A impressão que muitas vezes temos, ao lidar com raciocínios matemáticos, de que não há outra forma de executá-lo, tem sua origem não na imutabilidade e universalidade do conhecimento matemático, mas em poderosas convenções sociais que impregnam essa área do conhecimento humano. A compulsão sentida para seguirmos certos caminhos em um problema matemático é, segundo Bloor, uma compulsão social, associada ao mesmo tipo de compulsão que sentimos ao lidar com problemas morais. Nas duas ocasiões, parece não haver forma diferente de pensar ou agir, pois existem pesadas coerções sociais atuando sobre o indivíduo de forma a fazê-lo seguir o modo institucionalizado de agir. (DUARTE, 2007, p. 81).
\end{abstract}

Apesar da existência destas coerções, os princípios formais também podem ser "negociados", pois qualquer forma de conhecimento apresenta elementos dinâmicos, que permitem sua modificação. O conhecimento está sempre aberto a novas concepções e invenções, com possibilidades de reordenar a atividade matemática anterior. Uma nova forma de ver o mundo pode tornar-se a regra, tendo em vista que quaisquer regras podem ser reinterpretadas e desenvolvidas de novos modos. Assim, uma contradição pode vir a transformar-se em uma definição (renegociação); um modelo, num primeiro momento visto como um desvio em relação ao socialmente estabelecido, pode vir a transformar-se em uma definição aceitável. Então, "talvez aquilo que rejeitamos hoje como absurdo lógico parecerá,

\footnotetext{
${ }^{5}$ Em analogia à Kuhn, que afirma que durante a vigência de um paradigma há regras bem definidas sobre como um problema deve ser resolvido.
} 


\section{Norma e Desvio: ciência e sociedade na produção da ordem}

um dia, ser uma verdade autoevidente" (BLOOR, 1976, p. 168). Como argumentado acima, a verdade é aquilo que é aceito normalmente, sendo uma convenção social, passível de mudança.

Se a matemática versa sobre o número e suas relações, e se são criações sociais e convenções, então, a matemática versa sobre algo social. "É nesse sentido que é possível uma matemática alternativa, ou seja, um conhecimento matemático baseado em hábitos cognitivos institucionalizados alheios àqueles que existem em nossa sociedade" (DUARTE, 2007, p. 81). Em um sentido indireto, portanto, o conhecimento para Bloor versa sobre a sociedade, no mesmo sentido em que Durkheim diz que a religião versa sobre a sociedade.

\section{DO DESVIO À NORMALIDADE: CONTROVÉRSIAS E DISPUTAS NA CIÊNCIA}

O tratamento dos casos que não se conformam à maneira institucionalizada de pensar pode ser elucidada recorrendo-se a exemplos concretos, pois, como afirma Bloor: "ao ver como são resolvidas as disputas, passamos a notar o caráter convencional das forças que jazem latentes" (BLOOR, 1976, p. 251). A forma pela qual as disputas são resolvidas demonstram como fatores sociais influenciam no desenvolvimento da ciência, onde aparecem elementos como controvérsias e negociações. Esta forma de análise sociológica da ciência procura demonstrar que a produção do conhecimento científico não é determinada previamente, não possuindo um desenvolvimento totalmente racional, mas "mostra-se muitas vezes instável e até mesmo caótica quando observada mais de perto" (CUKIERMAN, 2007, p. 327).

O desenvolvimento científico é, no mesmo sentido em que Kuhn afirma, permeado por rupturas paradigmáticas, onde a cada vez uma espécie de fazer ciência domina o campo científico. Esta instabilidade que antecede a fase de ciência normal pode ser caracterizada como uma fase em que os grupos das comunidades científicas não se encontram sob a vigência de um paradigma, não possuindo problemas e soluções apontadas pelo próprio modelo de ciência normal.

A fase de mudança entre paradigmas diferentes traz consigo aquilo que os cientistas anteriormente desconsideravam como passível de ocasionar uma mudança na ciência: as anomalias. Estas abrem caminho para um novo desenvolvimento científico, em que emerge uma nova visão de mundo no interior dos grupos de cientistas, e onde encontramos um novo modelo de ciência normal, que traz consigo uma espécie de consenso no interior das comunidades. A fase de passagem de um modo de fazer ciência à outro revela-se, portanto, 


\section{NORUS v1, n.2, jan-jun 2014.}

permeado por disputas e controvérsias. A resolução destas leva o que anteriormente era considerado como um erro, ou um desvio no desenvolvimento científico, para aquilo que posteriormente torna-se a norma, o modo correto de fazer ciência.

A fim de aprofundar e ilustrar o argumento acima mencionado, recorremos ao caso do físico português João Magueijo que elabora uma teoria que vai contra um dos pilares da física moderna, ideia consagrada por Albert Einstein em sua teoria da relatividade restrita, qual seja, a afirmação de que a luz tem uma velocidade única e constante. É justamente esta ideia que Magueijo contesta e expõem em seu livro Mais rápido do que a velocidade da luz. Esta hipótese, primeiramente criticada e desconsiderada pela comunidade científica, vista como "impossível", segundo a teoria einsteiniana, recentemente foi alvo de experimentação por parte dos cientistas $^{6}$, abrindo a possibilidade de um novo desenvolvimento da teoria física. Esta mudança com relação às considerações relacionadas à teoria proposta por Magueijo demonstra uma possível modificação do paradigma físico, e apresenta um modelo prático do desenvolvimento científico, tal qual compreendido por autores como Kuhn, por exemplo.

Magueijo é um cosmólogo reconhecido internacionalmente, e que, desde a década de 1990 pretende, juntamente com alguns outros físicos, resolver alguns dos problemas da cosmologia. Nos últimos anos, e mais especificamente, nos últimos meses, sua teoria tem adquirido maior notoriedade, o que se tem traduzido numa presença frequente nos órgãos de comunicação, na sequência de vários trabalhos publicados, nos quais desenvolve um quadro alternativo para resolver os famosos enigmas do modelo de Big Bang do Universo.

Segundo a teoria do Big Bang, o universo teria surgido a partir de uma explosão inicial, encontrando-se atualmente em expansão. Entretanto, como se sabe, a teoria do Big Bang, sustentada por diversas provas concretas da sua evidência, sendo a mais aceita para explicar a origem e evolução do universo, ainda apresenta diversos problemas, para os quais esta teoria não obtém solução. Uma destas dificuldades consiste no problema cosmológico, decorrente de informações paradoxais associadas ao universo.

O problema cosmológico levanta-se quando o universo tinha menos de um segundo de existência. Se a luz se desloca no vácuo a cerca de $300.000 \mathrm{~km}$ por segundo, se a sua velocidade é constante, quando o universo tinha menos de 1 segundo de existência, a luz não tinha tempo de se propagar, e, se não se podia propagar, então também não poderia ocorrer qualquer tipo de interação física. Ora, não ocorrendo interação físicas, o universo não poderia ser homogêneo, como se verifica (CARVALHO, 2003, p. 99).

\footnotetext{
${ }^{6}$ A experiência que comprovaria a teoria de Magueijo foi realizada no laboratório do Centro Europeu de Investigação Nuclear (CERN), em Genebra, ao longo dos últimos três anos, e que somente agora foi divulgada.
} 


\section{Norma e Desvio: ciência e sociedade na produção da ordem}

Magueijo interroga-se se seria a inflação a verdadeira solução para os enigmas do Big Bang, avança, então, no sentido de elaboração de uma alternativa à cosmologia inflacionária: em vez de alterar o conteúdo material do universo, sustenta que a velocidade da luz não é constante, tendo sido maior no universo primordial, seguida de uma desaceleração para o seu valor atual. Para dar sustentação à sua hipótese Magueijo afirma que a teoria da velocidade variável da luz resolve um dos principais problemas da física moderna, mais especificamente, da cosmologia, sendo esta considerada como o estudo do universo como um todo. Com isto, portanto, conseguiria desenvolver um novo cenário onde grande parte dos referidos enigmas era resolvida.

Com esta hipótese, Magueijo contrapõe-se a uma das principais ideias da física einsteiniana, qual seja, o postulado da invariância da velocidade da luz, que é considerada como uma das constantes universais da física. Esta alteração, primeiramente admitida como uma simples hipótese de trabalho, não é aceita pela comunidade científica, por entrar em conflito com a física atual. Para podermos entender de que forma ambas divergem entre si, começaremos fazendo uma breve exposição da teoria einsteiniana da relatividade.

Einstein provocou uma revolução na teoria física, sem precedentes desde os tempos de Newton. Esta revolução deve-se à descoberta de uma anomalia na teoria deste, o que o levou a propor uma nova forma de fazer ciência. A anomalia até aquele momento não havia provocado o abandono da teoria newtoniana, pois era desconsiderada pelos cientistas. Para entendermos a causa disto, lembramos o que afirmam autores como Thomas Kuhn e David Bloor, a saber, que a simples descoberta de uma anomalia não leva a um abandono da teoria, para que isto de fato ocorra, outros elementos devem estar presentes, elementos sociais, que correspondem a negociações intergrupais e interesses, por exemplo. Bloor denomina a negação da possibilidade de desenvolvimento de outro paradigma como uma resistência à descoberta científica. A teoria einsteiniana, além de resolver o problema não solucionado à luz da teoria de Newton, ainda reproduzia todos os êxitos daquela.

Ao contrário da teoria newtoniana, que afirmava que o espaço e o tempo eram imutáveis, absolutos e autônomos,

Com o desenvolvimento da teoria da relatividade e a afirmação de que o valor das grandezas físicas (e não a relação entre estas grandezas) é relativo ao referencial, Einstein alterava a concepção newtoniana de espaço absoluto (e de tempo) em relação ao qual se dava o movimento (CARVALHO, 2003, p.98).

Assim, Einstein percebeu que, a ideia de espaço e de tempo deveriam ser relativas, caso a velocidade da luz fosse constante. 


\section{NORUS v1, n.2, jan-jun 2014.}

Desta forma, a teoria da relatividade elaborada por Einstein se assenta em dois postulados principais: o princípio da relatividade e o princípio da velocidade constante da luz. Portanto, uma das principais afirmações da teoria da relatividade de Einstein nos diz que o tempo e o espaço são relativos, ou seja, variam de um observador à outro: o que para um são acontecimentos simultâneos, não o são para outro. O tempo corre mais devagar para quem se move rapidamente, e as dimensões se contraem. "Para Einstein, o espaço-tempo podiam dobrar-se e variar, dilatar-se e encolher em função do movimento do observador em relação ao objeto observado. A única propriedade imutável do universo seria a velocidade da luz" (MAGUEIJO, 2003, p.13).

A teoria formulada por Magueijo forçava uma revisão de toda a estrutura da física, estabelecida por Einstein no começo do século XIX. Vejamos agora o que propõem Magueijo em sua teoria e de que forma ela se contrapõem a teoria da relatividade.

A teoria da velocidade da luz variável, proposta por Magueijo prevê que, de uma forma ou de outra, a velocidade da luz varia e é preciso rever a teoria da relatividade restrita, ou seja, um dos fundamentos da teoria einsteiniana. Em consequência disto, a maneira como esta teoria era vista por outros cientistas, mais experientes, levou seu parceiro, Andy, a abandonar a hipótese. Neste sentido, Bloor afirma que "por vezes, os cientistas irão avaliar que se ganha mais com a conformidade aos procedimentos e às teorias normais do que com seu afastamento" (BLOOR, 2008, p. 74). A sua formulação sofreu muitos ataques por parte de outros cientistas, sendo até mesmo chamada de "esotérica", em contraposição à científica, pelo fato de colocar em causa os pilares da relatividade e de grande parte dos conhecimentos físicos atuais.

Além disso, Magueijo afirma que a tarefa de contrariar e sustentar uma teoria radicalmente oposta a que era aceita pela comunidade científica revelava-se uma tarefa solitária e enfadonha, se pergunta então o que outros cientistas diriam se soubessem o que ele estava pesquisando, talvez o chamassem até mesmo de louco. Podemos perceber então que "no caminho da ciência não existe viagem solitária" (CUKIERMAN, 2007, p. 103), sendo imprescindível o apoio dos outros cientistas para a consolidação de uma nova forma de fazer ciência.

Como já era de se esperar, o processo para a publicação do artigo em que impunha sua hipótese foi lento e doloroso. Os argumentos utilizados para a reprovação do artigo muitas vezes nada tinham a ver com ciência, refletiam apenas a opinião segundo a qual tudo o que é novo é ruim, descrevendo a abordagem de Magueijo como pouco profissional, embora não apresentasse nenhuma razão científica para refutar seu argumento. Além disso, Magueijo 


\section{Norma e Desvio: ciência e sociedade na produção da ordem}

salienta que os relatórios emitidos pelos pareceristas refletiam apenas a posição social do autor ou suas boas ou más relações com o parecerista. Portanto, "como acontece com todas as seitas, [na ciência] quem não adere à linha oficial é segregado e perseguido" (MAGUEIJO, 2003, p. 259), ou não tem seus artigos publicados. Aqui podemos notar a operação de normas sociais que se expressam por meio da vergonha e do ostracismo.

Aparece, após a publicação do artigo, uma tarefa talvez mais desafiadora: que sua teoria fosse aceita pela comunidade científica. Esta tarefa revela-se mais difícil na medida em que a teoria não possui fundamentos empíricos, sendo considerada por este motivo, uma simples especulação. Temos aqui mais um exemplo da existência da operação de normas científicas, pois a afirmação de que "o conhecimento deve ser considerado fundamentalmente atrelado a tal aspecto da nossa experiência é uma norma social” (BLOOR, 2008, p. 55).

Recentemente, a teoria proposta por Magueijo é alvo de atenção por parte da comunidade científica, visto que uma equipe de cientistas registrou no mês de setembro de 2011 que partículas deslocaram-se a velocidades superiores às da luz, o que pode colocar em xeque definitivamente as teorias de Albert Einstein. Esta experiência foi realizada ao longo de três anos, e somente agora divulgada, elas demonstram que neutrinos, expelidos pelo laboratório do Centro Europeu de Investigação Nuclear (CERN), em Genebra, viajaram até Gran Sasso, na Itália, em um tempo 60 nanossegundos inferior ao que a luz demoraria. ${ }^{7}$

A conclusão do grupo de especialistas que participou da investigação agitou a comunidade científica, que repetiram milhares de vezes a experiência inicialmente realizada. Perguntamos então qual o motivo que levou, anteriormente, a essa recusa em aceitar a teoria elaborada por Magueijo, visto que ela demonstrou, recentemente, provas de sua adequação com a experiência e possível resolução dos problemas da cosmologia.

A resposta a esta questão possui relação com a consideração de que o desenvolvimento de uma nova teoria a respeito da origem do universo colocará em xeque toda a concepção de espaço, de tempo e de movimento considerado até então, ou seja, abre as portas para a emergência de um novo modo de ver o mundo e de praticar a ciência. A emergência deste novo paradigma teórico não diz respeito somente a questões científicas, mas também à dimensões sociais do conhecimento, visto que envolve não somente fatos, mas também instituições de ensino, disciplinas acadêmicas, programas de pesquisa, por exemplo.

A emergência da nova teoria envolve, portanto, todo um conjunto de métodos e práticas de pesquisa que a tomam como modelo teórico, o que requer que se modifique

\footnotetext{
7 Esta afirmação foi retirada de sites de divulgação científica, como Science, por exemplo: < http://www.sciencemag.org/content/334/6060/1200.full.pdf?sid=d7b89679-54da-41f2-bb87-1a943aa5f33e>, acessado em 04/12/2011.
} 


\section{NORUS v1, n.2, jan-jun 2014.}

também as próprias visões de mundo dos cientistas envolvidos no paradigma anterior. Esse processo, porém, demonstra ser lento, visto que requer muitas vezes que novos membros se incluam a uma determinada comunidade científica e comecem a praticar a ciência tal como estabelecida pelo novo paradigma.

Desta forma, observamos como uma cientista que tenta se contrapor a uma teoria que serve como paradigma a uma comunidade cientifica não é bem visto pelos demais colegas, especialmente os mais experientes da área de estudo. A prática científica, portanto, constrói obstáculos para a aceitação de uma nova teoria, mesmo que esta resolva de maneira mais eficientes os problemas encontrados.

Através do que foi anteriormente exposto, temos um exemplo da maneira pela qual as teorias científicas se formam e se constituem enquanto verdades científicas, sendo este um processo lento e que não depende apenas de fatores que dizem respeito à ciência, mas também fatores extracientíficos.

\section{CONCLUSÃO}

No artigo buscamos entender a dimensão normativa do pensamento de autores como Emile Durkheim, Thomas Kuhn, Harry Collins e David Bloor, procurando as raízes da ordem e da harmonia social, assim como as condições da transformação e da mudança social e científica, partindo-se de uma abordagem simétrica, buscando compreender tanto a dimensão correta/racional quanto aquilo que é considerado erro/desvio.

Através da exposição da teoria durkheimiana, compreendemos a sociedade como o fundamento de uma determinada forma de entendimento do mundo, visto que a religião serve como um exemplo de fato social, garantindo a coesão entre os membros do grupo, servindo como origem e forma de manutenção da integração social. As maneiras de agir e de pensar, que se impõe aos indivíduos, independentemente de suas vontades individuais, se deve ao fato de a sociedade ser o verdadeiro fundamento da religião.

Bloor compreende a ciência, assim como Durkheim compreende a religião, ressaltando aspectos ligados à uma dimensão social do conhecimento, e estendendo os fatores sociais para uma análise do conteúdo do conhecimento científico. Neste sentido, Bloor enfatiza a importância do consenso para a institucionalização de uma forma de conhecimento. O consenso faz com que a ciência se desenvolva de uma maneira estável. Porém a estabilidade do conhecimento não é permanente, visto que este sofre modificações, 


\section{Norma e Desvio: ciência e sociedade na produção da ordem}

poderíamos dizer, rupturas ao longo de seu desenvolvimento, que levam à emergência de uma nova maneira de fazer ciência.

Thomas Kuhn, da mesma forma, demonstra que a atividade científica ocorre em um sistema social que controla seus membros e suas atividades e veicula orientações e representações cognitivas, através do que ele chama de paradigmas. Se o cientista deixa de praticar a ciência definida por este ele estará abandonando também o paradigma do qual faz parte. Quem não segue as regras acaba sendo excluído da comunidade científica, tendo que "desenvolver seu trabalho isoladamente ou unir-se a algum grupo" (KUHN, 1962/1998, p. 39).

As regras que marcam o desenvolvimento da ciência, como formulado por Kuhn, e Bloor, pôde ser visualizado através do estudo das controvérsias que se estabeleceram na física, após a experimentação da teoria formulada por Magueijo. Este estudo de caso é, portanto, um exemplo da forma como a ciência constitui-se através de convenções sociais, onde a formulação de uma nova teoria revela-se lenta e difícil, como já mencionado anteriormente. Porém, isto demonstra também que a ciência não possui um desenvolvimento único e linear, mas constitui uma convenção instável, onde uma nova forma de fazer ciência emerge através das controvérsias e crises que caracterizam o desenvolvimento científico, e que transformam aquilo que anteriormente era visto como erro/desvio naquilo que torna-se a verdade/norma.

Através da exposição da teoria formulada pelos autores acima mencionados, percebemos que uma análise sociológica do conhecimento deve levar em conta tanto fatores sociais como aqueles relacionados à dimensão empírica. Neste sentido, o desenvolvimento da ciência não é visto como linear e não busca chegar a uma verdade, mas apresenta-se como um processo que possui semelhanças com os mecanismos de quebra de consenso que se manifestam na sociedade. Esta perspectiva pode abrir caminho para uma melhor compreensão das relações entre ciência e sociedade.

\section{REFERÊNCIAS BIBLIOGRÁFICAS}

ARON, Raymond. As etapas do pensamento sociológico. São Paulo: Martins Fontes, 2008. BLOOR, David. Conhecimento e imaginário social. São Paulo: UNESP, 1976/2008.

COLLINS, Harry. Cambiar el orden. Bernam: Universidade Nacional de Quilmes, 2009. 
NORUS v1, n.2, jan-jun 2014.

CRESPI, Franco; FORNARI, Fabrizio. Introdução à sociologia do conhecimento. Bauru, SP: EDUSC, 2000.

CARVALHO, Daniel. Relatividade e VSL: sobre o erro de Einstein. Revista da faculdade de Letras da Universidade do Porto, n. 20, p. 93-105, 2003.

DUARTE, Tiago. O Programa Forte e a busca de uma explicação sociológica das teorias científicas: constituição, propostas e impasses. Dissertação de Mestrado. Universidade Federal de Minas Gerais. 2007.

DURKHEIM. Emile. As regras do método sociológico. São Paulo: Companhia Editora Nacional, 1895/2002.

DURKHEIM, Emile. As formas elementares da vida religiosa. São Paulo: Martins Fontes, 1996/1912.

DURKHEIM, Emile. O ensino da moral na escola primária. Novos Estudos Cebrap, São Paulo, n 78 , p. 59-75, jun. 2007.

KUHN, Thomas. A estrutura das revoluções científicas. São Paulo: Perspectivas, 1962/1998.

LALLEMENT, Michel. História das idéias sociológicas. Das origens a Max Weber. Petrópolis: Vozes, 2003.

LATOUR, Bruno. Ciência em ação: como seguir cientistas e engenheiros sociedade afora. São Paulo: Editora UNESP, 1998/2000.

MAGUEIJO, João. Mais rápido que a velocidade da luz: a história de uma especulação científica. Rio de Janeiro: Record, 2003.

MATTEDI, Marcos; SPIESS, Maiko. Modalidades de regulação da atividade científica: uma comparação entre as interpretações normativas, cognitiva e transacional dos processos de integração social da comunidade científica. Educação e Sociedade, Campinas, v. 31, n. 110, p. 73-92, jan./mar., 2010.

MOSER, Paul; MULDER, Dwayne; TROUT, J. A teoria do conhecimento: uma introdução temática. São Paulo: Martins Fontes, 2004.

OLIVA, Alberto. Ciência e sociedade: do consenso à revolução. Porto Alegre: EDIPUC RS, 1999. 